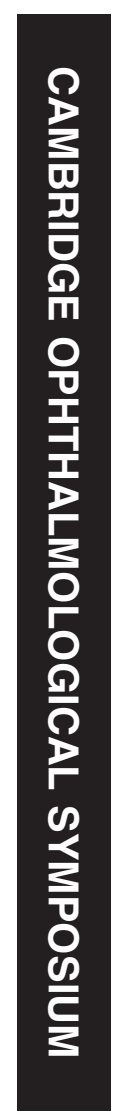

\section{The pathology of ocular cancer}

\author{
Abstract \\ Primary cancers of the eye are rare. These \\ include uveal melanoma, a tumor that \\ preferentially affects the choroid of light- \\ eyed, fair-skinned Europeans, and the \\ pediatric retinal neoplasm retinoblastoma, \\ which is slightly more common worldwide. \\ Uveal melanoma kills about half of affected \\ patients. Most succumb to hepatic metastases, \\ which are unresponsive to current therapy. \\ Factors indicative of poor prognosis include \\ tumor size, ciliary body involvement, \\ epithelioid cells, extraocular extension, \\ lymphocytic and melanophagic infiltration, \\ mitotic activity, vascular mimicry patterns, \\ and most importantly, the detection of \\ monosomy 3 and class 2 gene expression \\ profile in tumor cells using special tests. \\ Most retinoblastomas are caused by sporadic \\ somatic mutations in the $R B 1$ gene, but about \\ one-third arise in infants with germline \\ mutations. The latter tend to develop earlier, \\ are often bilateral and are transmissible to \\ offspring as an autosomal dominant trait. \\ Retinoblastoma displays varying degrees of \\ differentiation including Homer Wright and \\ Flexner-Wintersteiner rosettes and \\ photoreceptor differentiation (fleurettes). \\ Rosettes are more common in eyes enucleated \\ from very young infants. Tumors composed \\ entirely of fleurettes (retinoma/retinocytoma) \\ are thought to be retinoblastoma precursors, \\ and like retinoblastoma, harbor mutations in \\ both copies of the $R B 1$ gene. Retinoblastoma \\ is a major cancer treatment success story in \\ developed countries where most deaths are \\ caused by secondary tumors in germline \\ mutation carriers. High-risk histopathological \\ features that are an indication for adjuvant \\ chemotherapy include massive uveal invasion \\ and retrolaminar optic nerve invasion. \\ Eye-sparing therapies including \\ brachyradiotherapy and systemic \\ and intra-arterial chemotherapy have \\ reduced the number of eyes with \\ retinoblastoma requiring enucleation in \\ recent years.
}

\author{
Accepted in revised form: \\ 8 October 2012 \\ Published online: \\ 16 November 2012 \\ Tel: +1 215928 3280; \\ Fax: +1 2158254703 \\ E-mail: reagle@willseye.org
}

RC Eagle $\mathrm{Jr}^{1,2}$

Eye (2013) 27, 128-136; doi:10.1038/eye.2012.237;

published online 16 November 2012

Keywords: eye cancer; introduction; uveal melanoma; retinoblastoma

This review will focus on the two most common primary malignant intraocular neoplasms, retinoblastoma and uveal melanoma.

(Figure 1) Post-mortem studies suggest that the most common intraocular malignancy is secondary uveal involvement by metastatic carcinoma. ${ }^{1}$

Primary malignant intraocular neoplasms are relatively rare. Kivëla ${ }^{2}$ has estimated that 6679-7095 cases of uveal melanoma and 7202-8102 cases of retinoblastoma occur yearly in the world. Although the United States comprises only $4.5 \%$ of the world's population, 2100 cases of eye cancer occur there yearly, reflecting the high proportion of its citizens who are of European descent. The incidence of intraocular tumors varies markedly depending on the age and ethnicity of patient population. A study from New York city reported that the annual age-adjusted incidence (per million population) of uveal melanoma was 0.31 in black patients, 0.38 in Asian patients, 1.67 in Hispanic patients, and 6.02 in non-Hispanic white patients. ${ }^{3}$ Using these incidence figures we estimate that two-thirds of uveal melanomas develop in white patients of European descent who comprise only $13 \%$ of the world's 7 billion people. In contrast, $<8 \%$ of the world's melanomas occur in people of Han Chinese and Bengali descent who comprise nearly onequarter of the world's population. ${ }^{4}$ Uveal melanoma's propensity for lightly pigmented patients and the posterior part of the uveal tract suggests that UV light may have a role in its pathogenesis, but several studies in this regard are inconclusive. ${ }^{5,6}$ Although retinoblastoma is the most common eye cancer on a worldwide basis, uveal melanoma is the most common ocular cancer in Europe and the United States, exceeding retinoblastoma by a factor of 6 . 


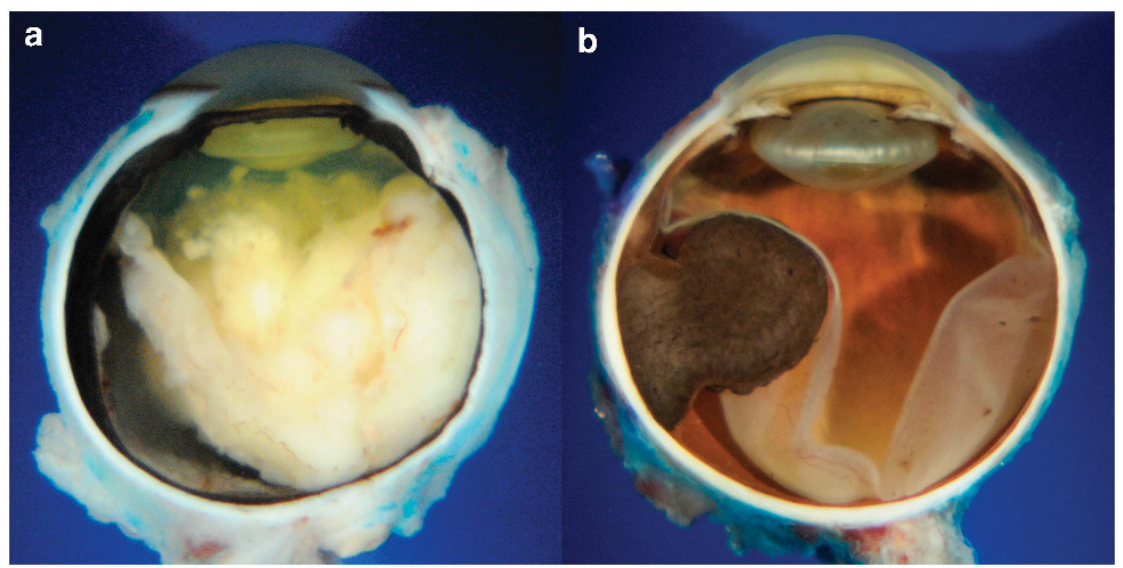

Figure 1 Primary intraocular cancers. Retinoblastoma (a) and uveal melanoma (b) are the most common primary intraocular cancers. Retinoblastoma is the most common worldwide.

Neoplasms derived from uveal melanocytes include benign nevi and malignant melanomas that can arise in the iris, ciliary body and/or choroid. More than $90 \%$ of these are choroidal tumors. ${ }^{7}$ Initially dome- or oval-shaped, choroidal melanomas frequently rupture through Bruch membrane and assume a characteristic mushroom or collar stud configuration. ${ }^{8}$

Cancer is a genetic disease characterized by genomic instability and the progressive accumulation of genetic abnormalities or mutations. Fifty percent of uveal melanomas harbor mutations in the GNAQ gene that encodes a G-protein-coupled receptor in the RAF/MEK/ ERK pathway. Also found in benign precursor lesions, such as congenital ocular melanocytosis ${ }^{9-11}$ GNAQ mutations are thought to be an early or initiating event in the pathogenesis of uveal melanoma.

Nevi and melanomas comprise a disease spectrum. Tumors become progressively less differentiated and develop the ability to metastasize as mutations accumulate and chromosomes or chromosomal fragments are lost or gained. The expression of genes in uveal melanomas changes as tumors undergo malignant transformation..$^{12-14}$ Gene expression profile (GEP) analysis has identified two classes of tumors that differ markedly in their metastatic potential. ${ }^{14}$ The GEP of lowgrade (Class I) melanomas resembles melanocytes. Class I tumor rarely metastasize $(<5 \%)$. In contrast, the GEP of class 2 tumors, which have more than a $90 \%$ risk for metastasis, resembles that of primitive neural or ectodermal stem cells. ${ }^{15}$ In addition, class 2 tumors typically have major chromosomal abnormalities such as loss of chromosome 3 (monosomy 3 ) and/or amplification of the long arm of chromosome $8(8 \mathrm{Q})$, which are important prognostic indicators. ${ }^{16-20}$ They also manifest histopathological markers of malignant behavior such as epithelioid cell morphology and vascular mimicry patterns. Eighty-four percent of class II melanomas harbor inactivating mutations in the BAP1 (breast cancer 1, early onset (BRCA1)-associated protein-1 gene). The BAP1 gene is located on chromosome 3 and inactivating mutations are disclosed by loss of chromosome $3 .{ }^{21}$ A proprietary GEP assay using a microarray of only 13 genes has been reported to be the most accurate prognostic marker for melanoma mortality and metastasis, although this remains controversial. ${ }^{22,23}$

Although greatly inferior to chromosomal analysis and GEP, clinical examination and routine histopathological examination of uveal melanoma can reveal a number of important prognostic factors. Tumor size (largest tumor diameter and thickness) and the presence or absence of ciliary body involvement and extraocular extension are the most important factors that can be determined on clinical examination. Tumor size and ciliary body involvement are used to prognostically stratify melanomas in the TMN classification in the seventh edition of the AJCC Cancer Staging Manual. ${ }^{24}$ Tumor size is an important predictor of metastasis. A study of a large series of uveal melanomas at the Armed Forces Institute of Pathology (AFIP) showed that the 15-year mortality of small tumors (defined as $<10 \mathrm{~mm}$ in largest tumor diameter) was $30 \%$ compared with $65 \%$ if the tumor was larger than $15 \mathrm{~mm} .{ }^{25} \mathrm{~A}$ simplified system that estimates prognosis from tumor thickness has been published. ${ }^{7}$ In that study of $>8000$ uveal melanomas, each millimeter increase in tumor thickness imparted a 1.06 hazard ratio. ${ }^{5}$ Not surprisingly, class 2 GEP and monosomy 3 are more common in larger tumors.

Cell type is another important prognostic indicator that is assessed during routine histopathological examination. ${ }^{25}$ Cell type refers to cytological characteristics of the melanoma cells that initially were linked to prognosis by Callender in $1931 .{ }^{26}$ Modified by 
McLean et $a l^{27}$ in 1983, the Callender classification includes spindle cell nevi and spindle cell melanomas, mixed cell melanomas and epithelioid melanomas in order of increasing mortality. The appearance of melanoma cells evolves as they accumulate mutations and become progressively less differentiated. (Figures 2 and 3) Nuclear characteristics are particularly important in the histopathological assessment of uveal melanocytic tumors. Initially slender and cigar-shaped with finely dispersed chromatin, spindle cell nuclei become progressively plumper and oval in shape as they become less differentiated, and eventually become round in epithelioid melanoma cells. Concurrently, the nuclear chromatin coarsens, eventually clumping on the inner aspect of the nuclear membrane (peripheral margination of chromatin) of epithelioid cells. Spindle A nuclei lack nucleoli, but typically have a longitudinal 'chromatin stripe' that reflects a fold in the nuclear membrane. Nucleoli are a characteristic feature of spindle B cells and they become progressively larger as melanoma cells become less differentiated. Large reddish-purple nucleoli are a characteristic feature of epithelioid melanoma cells. The cytoplasmic characteristics of melanoma cells also change. Spindle cells have indistinct cytoplasmic margins and typically form a syncytium. Individual cells are fusiform or spindle in configuration with long tapering processes that occasionally are evident histopathologically when isolated pigmented cells occur in a largely amelanotic tumor. Spindle cells are arranged in a parallel manner and often form interweaving bundles. Epithelioid cells are round or polygonal in shape and they often are poorly cohesive with distinct cytoplasmic margins.

As noted above, the biological spectrum of melanoma cells has been parceled into two types of spindle cells (spindle A and B) and epithelioid cells. This separation is somewhat arbitrary and the classification of cells can be subjective in practice. The experience of the pathologist undoubtedly has a role, but Gamel and McLean ${ }^{28}$ demonstrated that even experienced ophthalmic pathologists differ when they attempt to classify individual melanoma cells. Furthermore, some tumors may be difficult to classify. Not infrequently, melanomas contain spindle cells whose nuclear characteristics are intermediate between spindle B and epithelioid. Similarly, distinguishing between nevus cells and low-grade spindle melanoma cells can be challenging.

Currently, most uveal melanomas are treated with plaque brachytherapy, because the Collaborative Ocular Melanoma Study showed that survival of medium-sized tumors after this eye-sparing treatment and enucleation

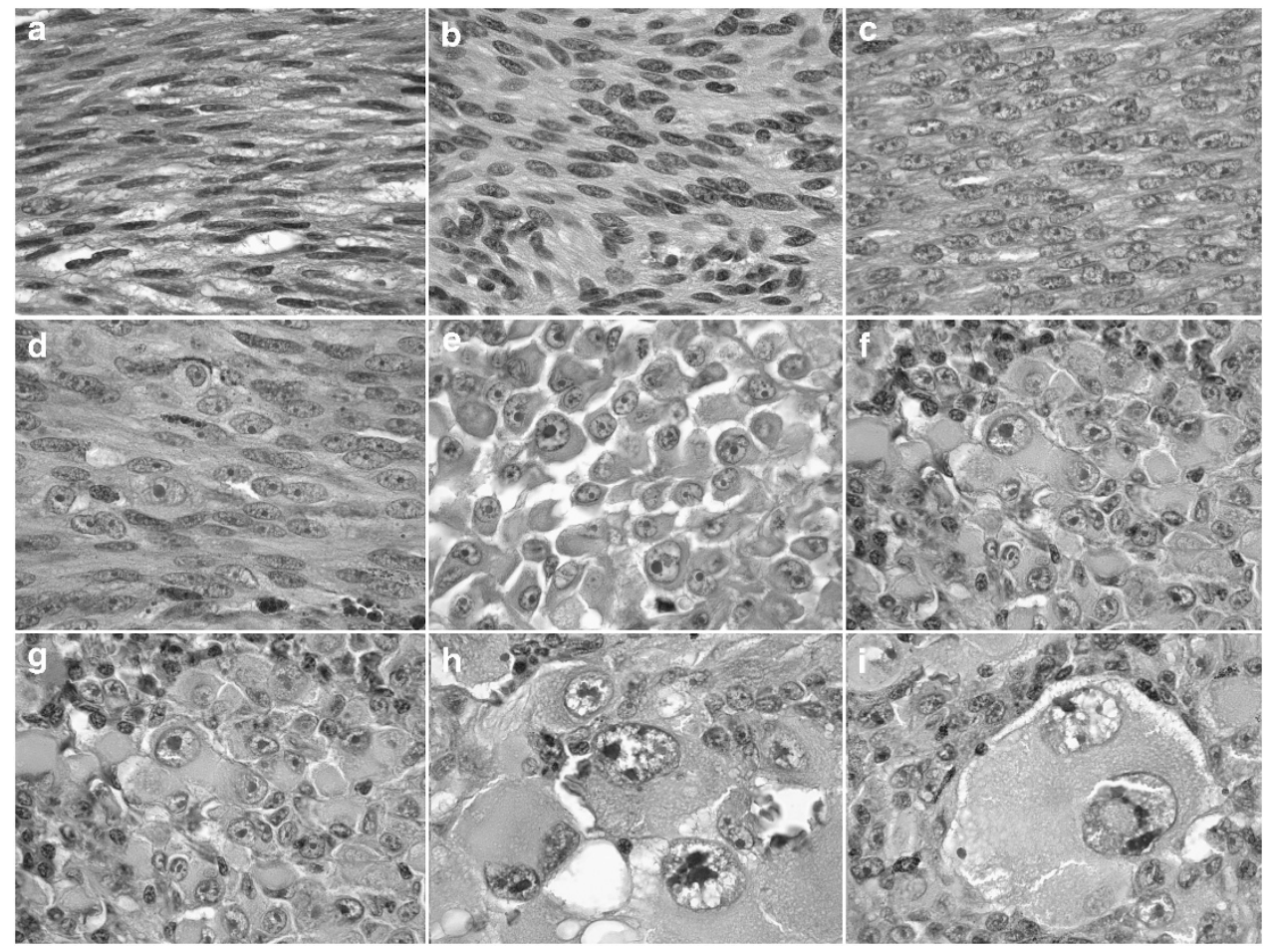

Figure 2 The biological spectrum of uveal melanoma includes bland spindle cells at one end and markedly anaplastic epithelioid tumor giant cells at the other. Fusiform spindle cells $(\mathrm{a}-\mathrm{d}$ ) have indistinct cytoplasmic borders and form syncytia. Epithelioid cells (e-i) are poorly cohesive. The prognosis of uveal melanomas that contain epithelioid cells is poorer. All figures, Hematoxylin and eosin, original magnification $\times 100$. 

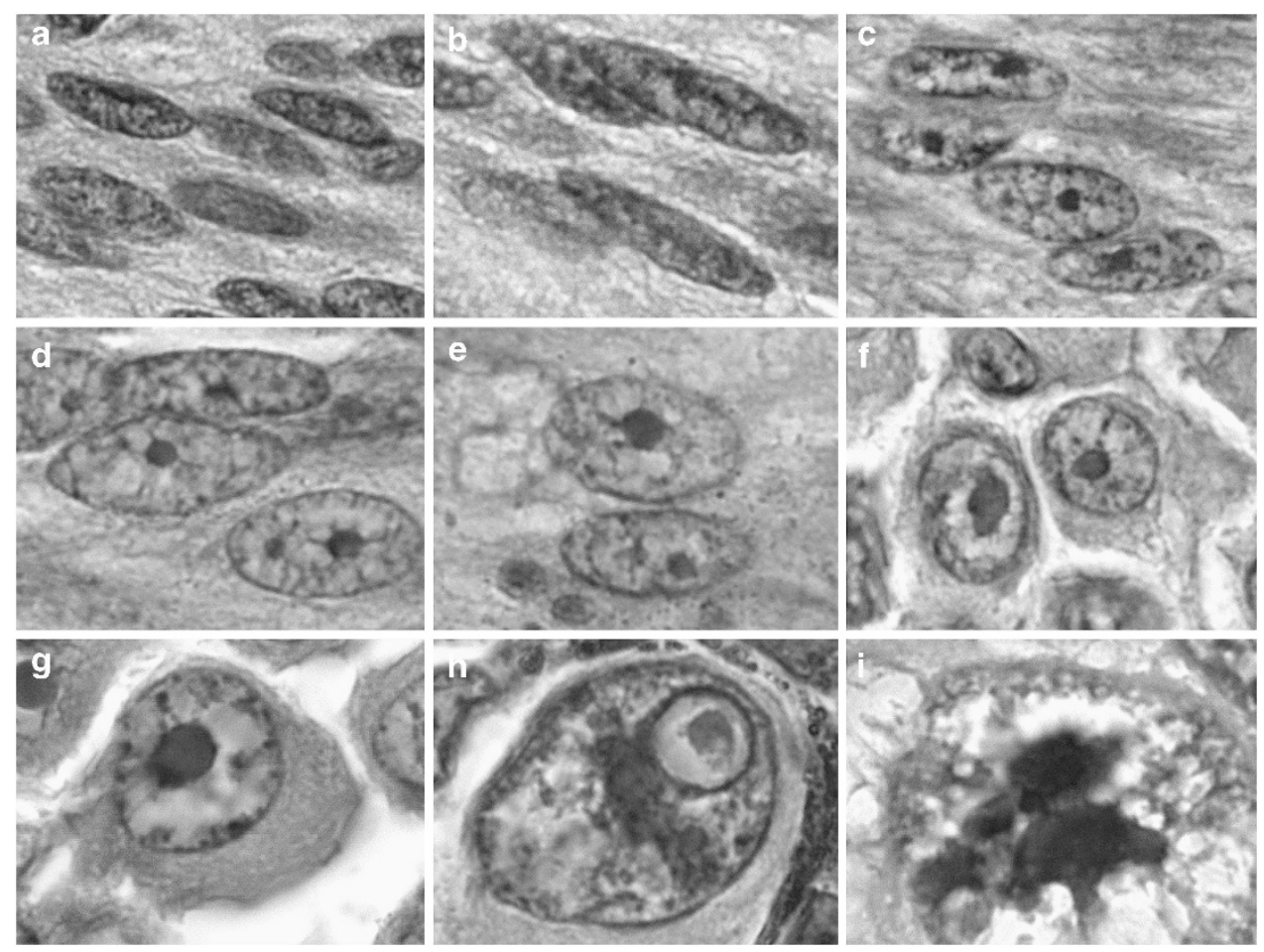

Figure 3 The biological spectrum of uveal melanoma: nuclear characteristics. As the degree of differentiation decreases, melanoma cell nuclei become progressively rounder, nucleoli appear and increase in size, and chromatin coarsens and marginates. Spindle A cells are seen in (a), Spindle B cells in (b-d), epithelioid cells in (f) and (g), and anaplastic tumor giant cells in (h) and (i). Nuclei in (e) are intermediate between spindle B and epithelioid. All figures, hematoxylin and eosin, original magnification $\times 400$.

are similar. ${ }^{29}$ Most larger melanomas that are enucleated are mixed cell melanomas that contain a mixture of spindle and epithelioid cells. ${ }^{6}$

Other prognostic factors that can be assessed during routine histopathological examination include tumor location, mitotic activity, the presence or absence of extrascleral invasion, lymphocytic and melanophagic infiltration, and vascular mimicry patterns.

Ciliary body tumors tend to have a poorer prognosis than choroidal tumors. ${ }^{30,31}$ Delayed diagnosis, larger size, or perhaps intrinsic biological factors such as more malignant cytology or a higher incidence of microvascular or chromosomal abnormalities might be responsible for poorer prognosis. Diagnosis of ciliary body melanoma may be delayed because the tumors are hidden behind the iris and they often do not produce retinal detachment, which typically is responsible for visual loss, uveal melanoma's most common presenting symptom.

Mitoses are relatively infrequent in uveal melanoma and typically are assessed by counting the number in 40 high power fields. Less than ten mitotic figures are counted in many cases. The percentage of cycling cells disclosed by immunohistochemical proliferation marker
Ki-67 also is typically low. ${ }^{32}$ The presence of infiltrating lymphocytes in uveal melanoma is another poor prognostic sign. ${ }^{33,34}$ This seemingly counterintuitive finding is based on the immune-privileged status of the eye. Extraocular dissemination of melanoma cells is required for stimulation of a T-cell-mediated immune response. Increased numbers of infiltrating melanophages also are associated with poorer prognosis. ${ }^{35}$

The presence of so-called vascular mimicry patterns, whose detection is enhanced by staining with periodic acid-Schiff, also carries a poorer prognosis. ${ }^{36,37}$ These patterns initially were called vascular loops and networks or extracellular matrix patterns. Tumors that have extended extrasclerally, have invaded the lumen of a vortex vein, or invaded the subarachnoid space of the optic nerve are also considered to have poorer prognosis. ${ }^{38}$

As discussed previously, the prognosis of uveal melanoma is most accurately determined using molecular biological techniques to assess tumors for nonrandom chromosomal abnormalities or GEP. Patients (50\%) who have monosomy 3 in their tumor cells will die within 3 years. ${ }^{16}$ Patients with disomy 3 have a poorer 
prognosis if there is amplification of $8 \mathrm{q} \cdot{ }^{17}$ As noted above, GEP discloses two classes of uveal melanomas that differ markedly in risk for metastasis. ${ }^{14}$

Uveal melanoma typically metastasizes to the liver, which is involved in $90 \%$ of cases. ${ }^{39}$ Studies based on tumor doubling times suggest that uveal melanomas destined to metastasize already have spawned clinically unapparent distant micrometases before the patient becomes symptomatic and consults an ophthalmologist. ${ }^{40}$ Hence, it is probable that the ocular oncologist merely achieves local control in most cases, and has little or no effect on systemic outcome.

Furthermore, there currently is no effective treatment for metastatic uveal melanoma; $80 \%$ of affected patients succumb to their metastatic tumor within 1 year. ${ }^{41}$ Late metastases do occur in some cases.

\section{Retinoblastoma}

Throughout most of the world, the pediatric malignant retinal neoplasm retinoblastoma is the most common primary intraocular tumor, reflecting the rarity of uveal melanoma in the more heavily pigmented people of Asia, Africa and South America. Although uveal melanoma is about seven times more common than retinoblastoma in the United States, retinoblastoma is 3-4 times more common than melanoma in India and is also more common in Africa, South America, and other parts of Asia.

Although rare cases have been reported in teenagers and adults, retinoblastoma usually occurs in infants at a mean age of 18 months. ${ }^{42}$ Familial cases or sporadic cases arising in patients with germline mutations in the retinoblastoma ( $R B 1$ ) gene occur earlier (mean age 12 months) compared with the majority of cases that spawned by sporadic somatic mutations in the RB1 gene (mean age 2 years).

Located on the long arm of chromosome 14 (13q1-4), the retinoblastoma or $R B 1$ gene is the paradigmatic recessive oncogene. ${ }^{43-45}$ The $R B 1$ gene product is involved in the regulation of the cell cycle and its function is modulated by a phosphorylation/ dephosphorylation mechanism during cell proliferation and differentiation. Retinoblastoma develops if both copies of the RB1 gene are lost or inactivated. The majority of retinoblastomas arise sporadically and are caused by somatic mutations; both copies of the RB1 gene are lost or inactivated in a single retinal cell. However, one-fourth of sporadic cases are caused by new germline mutations. Such tumors often affect both eyes and can be passed on to offspring in an autosomal dominant manner. Carriers of familial retinoblastoma are heterozygous for RB1 gene mutations; only a single somatic mutation affecting the remaining allele in a retinal cell is required for malignant transformation. Carriers who harbor germline mutations also are predisposed to a variety of secondary neoplasms (20-50\% incidence in 20 years). ${ }^{46,47}$ These include osteogenic and other soft tissue sarcomas in the field of external beam radiation, which has led clinicians to largely abandon that treatment in recent years.

The genetics of retinoblastoma actually are more complicated than initially thought. Dimaras et $a l^{48}$ have shown that both copies of the RB1 gene are also lost or inactivated in well-differentiated, benignly-behaving precursor tumors called retinomas or retinocytomas, which typically exhibits advanced degrees of photoreceptor differentiation (fleurettes). A number of additional mutations are required for malignant transformation into retinoblastoma. Recently, Gallie's laboratory has described rare cases of retinoblastoma-like tumors that lack mutations in the RB1 gene. ${ }^{49}$ These are found in very young infants and the tumor cells typically have multiple nucleoli and express high levels of MYCN.

Retinblastoma arises from and destroys the neurosensory retina. Endophytic tumors arise from the inner layers of the retina, which remains attached. They invade the vitreous cavity and occasionally seed the anterior chamber. Exophytic retinoblastomas, which arise from outer retinal layers, typically cause high bullous retinal detachments that may abut the back of the lens, causing anterior displacement of the lens-iris diaphragm and secondary angle closure. In eyes with large tumors, the growth pattern is often combined or indeterminate.

In developed countries, retinoblastoma typically presents with a white pupillary reflex (leukocoria), and/ or strabismus due to visual loss. A relatively rare $(1.5 \%$ of cases) growth pattern called diffuse infiltrative retinoblastoma occurs in older children (mean age 6 years). ${ }^{50}$ In such cases, the retina is diffusely thickened by tumor, does not form a distinct tumefaction and usually lacks calcification. Tumor cells typically blanket the ciliary body, infiltrate the zonule and seed the anterior chamber forming a pseudohypopyon of tumors cells that may be misinterpreted as inflammation, leading to an inappropriate invasive procedure. Aseptic orbital cellulitis is another rare pseudo-inflammatory presentation of retinoblastoma typically found in eyes with large tumors and severe secondary neovascular glaucoma that has caused total ischemic infarction of the tumor and other intraocular structures as well. ${ }^{51}$

Because the retina is a colony of brain-like cells, it is not surprising that retinoblastoma has a encephaloid appearance macroscopically. The white tumor typically contains scattered flecks of lighter-colored material that correspond to foci of dystrophic calcification within necrosis. Microscopically, retinoblastoma is composed of mitotically active, poorly-differentiated neuroblastic cells 
that have irregular basophilic nuclei and scanty cytoplasm. Apoptosis is common as well.

Retinoblastoma cells are prone to undergo ischemic necrosis that typically occurs when the growing cells extend 90-110 microns from a vessel. ${ }^{52}$ Viable cells persist as basophilic sleeves and cuffs about 200 microns in diameter (inappropriately termed pseudorosettes) that may impart a papillary appearance to the tumor under lower magnification. The basophilic cuffs are separated by sheets of necrotic tumor, which is eosinophilic because the cells have lost their basophilic nuclear DNA.

Dystrophic calcification, which appears reddish purple in hematoxylin and eosin (H\&E) sections, often develops in the necrotic areas. Hence, retinoblastoma appears blue, pink and purple in routine H\&E sections. The detection of calcification within retinoblastoma by various imaging techniques is a helpful diagnostic adjunct clinically.

Retinoblastoma exhibits varying degrees of retinal differentiation, which tends to become less evident with increasing age..$^{53-55}$ These include advanced photoreceptor differentiation (fleurettes), early retinal differentiation (classic Flexner-Wintersteiner rosettes with a central lumen analogous to the subretinal space), and more primitive neuroblastic differentiation evident as Homer Wright rosettes. (Figure 4) In the latter, a ring of nuclei surrounds a central tangle of neural filaments. Homer Wright rosettes also occur in other tumors such as neuroblastoma. Flexner-Wintersteiner rosettes are more common in retinoblastomas enucleated from very young infants. Tumors in older infants tend to be poorly differentiated. ${ }^{56}$

Foci of photoreceptor differentiation are found histopathologically in about one-fifth of enucleated tumors. ${ }^{56}$ Unlike Flexner-Wintersteiner rosettes, which decrease with increasing age, photoreceptor differentiation probably persists because significant degrees of apoptosis and cellular turnover are absent in these highly differentiated areas of tumor. Bland tumors composed entirely of photoreceptor differentiation called retinomas or retinocytomas are thought to be precursors of retinoblastoma. ${ }^{48}$ Foci of photoreceptor differentiation observed in the basal part of endophytic retinoblastomas provides evidence for this hypothesis. ${ }^{56}$

Untreated retinoblastoma is almost universally fatal. The risk for death from direct infiltration of the CNS or distant metastasis increases as growing tumor invades the optic nerve or breaches Bruch membrane to reach the highly vascular tissues of the posterior uvea. Anterior chamber involvement with iris stromal invasion and/or infiltration of aqueous outflow pathways are also thought to affect prognosis adversely. Anterior retinoblastomas that erode through the sclera or transit scleral emissarial canals can gain access to conjunctival lymphatics and metastasize to regional lymph nodes.
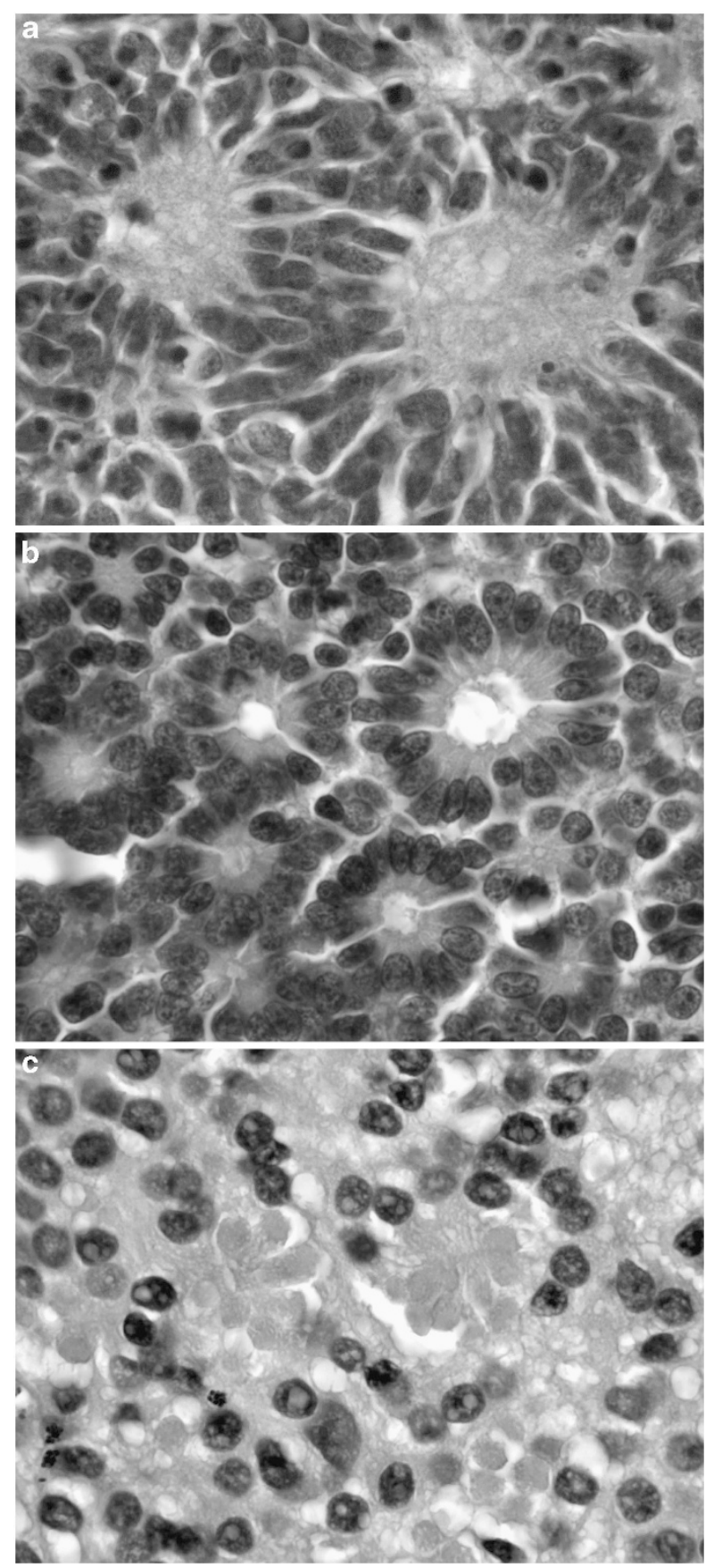

Figure 4 Retinoblastoma, increasing degrees of retinal differentiation. (a) Primitive Homer Wright rosettes (neuroblastic differentiation). (b) Flexner-Wintersteiner rosettes (early retinal differentiation) (c) Photoreceptor differentiation (fleurettes). All figures, hematoxylin and eosin, original magnification $\times 250$.

Two of the most important features that can be detected on routine histopathological examination and are considered high-risk factors for distant metastasis are massive invasion of the posterior uvea, and invasion of the optic nerve that extends behind the lamina cribrosa, or even more significantly, the surgical margin of 
resection. ${ }^{56}$ Both are considered indications for adjuvant chemotherapy in most centers. Retrolaminar invasion of the optic nerve is important because tumor cells behind the lamina essentially are outside the eye. Any degree of concurrent non-massive uveal invasion combined with any degree of prelaminar optic nerve invasion was another indication for adjuvant chemotherapy is a recent large prospective clinical trial. Massive choroidal invasion has been defined as being greater than $3 \mathrm{~mm}$ in diameter, or involving the full thickness of the choroid. ${ }^{57}$

Adequate histopathological evaluation of enucleated eyes with retinoblastoma requires high quality microscopic sections prepared from the main PO block that include the central part of the longitudinal-sectioned optic nerve and the lamina cribrosa. In addition, both calottes should be sectioned in a bread-loaf manner and submitted entirely to exclude uveal involvement that may not be evident macroscopically. ${ }^{58}$ Experienced ophthalmic pathologists who can differentiate artifactitous contamination of the uvea by tumor from true uveal stromal invasion also are necessary.

New therapies for retinoblastoma introduced in recent years include several methods for administering chemotherapy as well as plaque brachytherapy. ${ }^{59-63}$ As a result, fewer eyes with retinoblastoma are being enucleated.

\section{Conflict of interest}

The author declares no conflict of interest.

\section{References}

1 Nelson CC, Hertzberg BS, Klintworth GK. A histopathologic study of 716 unselected eyes in patients with cancer at the time of death. Am J Ophthalmol 1983; 95: 788-793.

2 Kivelä T. The epidemiological challenge of the most frequent eye cancer: retinoblastoma, an issue of birth and death. Brit J Ophthalmol 2009; 93: 1129-1131.

3 Hu DN, Yu GP, McCormick SA, Schneider S, Finger PT. Population-based incidence of uveal melanoma in various races and ethnic groups. Am J Ophthalmol 2005; 140: 612-617.

4 Lists of Ethnic Groups. http://en.wikipedia.org/wiki/ Lists_of_ethnic_groups.

5 Shah CP, Weis E, Lajous M, Shields JA, Shields CL. Intermittent and chronic ultraviolet light exposure and uveal melanoma: a meta-analysis. Ophthalmology 2005; 112: 1599-1607.

6 Schmidt-Pokrzywniak A, Jöckel KH, Bornfeld N, Sauerwein $\mathrm{W}$, Stang A. Positive interaction between light iris color and ultraviolet radiation in relation to the risk of uveal melanoma: a case-control study. Ophthalmology 2009; 116: 340-348.

7 Shields CL, Furuta M, Thangappan A, Nagori S, Mashayekhi A, Lally DR et al. Metastasis of uveal melanoma millimeter-by-millimeter in 8033 consecutive eyes. Arch Ophthalmol 2009; 127: 989-998.
8 Albert DM, Diener-West M, Robinson NL, Grossniklaus HE, Green WR. Histopathologic characteristics of uveal melanomas in eyes enucleated from the Collaborative Ocular Melanoma Study. COMS report no. 6. Am J Ophthalmol 1998; 125: 745-766.

9 Onken MD, Worley LA, Long MD, Duan S, Council ML, Bowcock AM et al. Oncogenic mutations in GNAQ occur early in uveal melanoma. Invest Ophthalmol Vis Sci 2008; 49: 5230-5234.

10 Van Raamsdonk CD, Bezrookove V, Green G, Bauer J, Gaugler L, O'Brien JM et al. Frequent somatic mutations of GNAQ in uveal melanoma and blue naevi. Nature 2009; 457: 599-602.

11 Van Raamsdonk CD, Griewank KG, Crosby MB, Garrido MC, Vemula S, Wiesner Tet al. Mutations in GNA11 in uveal melanoma. N Engl J Med 2010; 363: 2191-2199.

12 Zuidervaart $\mathrm{W}$, van der Velden PA, Hurks MH, van Nieuwpoort FA, Out-Luiting CJ, Singh AD et al. Gene expression profiling identifies tumour markers potentially playing a role in uveal melanoma development. Br J Cancer 2003; 89: 1914-1919.

13 Tschentscher F, Hüsing J, Hölter T, Kruse E, Dresen IG, Jöckel KH et al. Tumor classification based on gene expression profiling shows that uveal melanomas with and without monosomy 3 represent two distinct entities. Cancer Res 2003; 63: 2578-2584.

14 Onken MD, Worley LA, Ehlers JP, Harbour JW. Gene expression profiling in uveal melanoma reveals two molecular classes and predicts metastatic death. Cancer Res 2004; 64: 7205-7209.

15 Chang SH, Worley LA, Onken MD, Harbour JW. Prognostic biomarkers in uveal melanoma: evidence for a stem cell-like phenotype associated with metastasis. Melanoma Res 2008; 18: 191-200.

16 Prescher G, Bornfeld N, Hirche H, Horsthemke B, Jöckel $\mathrm{KH}$, Becher R et al. Prognostic implications of monosomy 3 in uveal melanoma. Lancet 1996; 347: 1222-1225.

17 Sisley K, Rennie IG, Parsons MA, Jacques R, Hammond DW, Bell SM et al. Abnormalities of chromosomes 3 and 8 in posterior uveal melanoma correlate with prognosis. Genes Chromosomes Cancer 1997; 19: 22-28.

18 White VA, Chambers JD, Courtright PD, Chang WY, Horsman DE. Correlation of cytogenetic abnormalities with the outcome of patients with uveal melanoma. Cancer 1998; 83: 354-359.

19 Damato B, Dopierala JA, Coupland SE. Genotypic profiling of 452 choroidal melanomas with multiplex ligationdependent probe amplification. Clin Cancer Res 2010; 16 : 6083-6092.

20 Shields CL, Ganguly A, Materin MA, Teixeira L, Mashayekhi A, Swanson LA et al. Chromosome 3 analysis of uveal melanoma using fine-needle aspiration biopsy at the time of plaque radiotherapy in 140 consecutive cases: The Deborah Iverson, MD, Lectureship. Arch Ophthalmol 2007; 125: 1017-1024.

21 Harbour JW, Onken MD, Roberson ED, Duan S, Cao L, Worley LA et al. Frequent mutation of BAP1 in metastasizing uveal melanomas. Science 2010; 330: 1410-1413.

22 Onken MD, Worley LA, Tuscan MD, Harbour JW. An accurate, clinically feasible multi-gene expression assay for predicting metastasis in uveal melanoma. J Mol Diagn 2010; 12: $461-468$. 
23 Onken MD, Worley LA, Char DH, Augsburger JJ, Correa ZM, Nudleman E et al. Collaborative Ocular Oncology Group report number 1: prospective validation of a multi-gene prognostic assay in uveal melanoma. Ophthalmology 2012; 119: 1596-1603.

24 Edge SB, Byrd DR, Compton CC, Fritz AG, Greene FL, Trotti AM (eds). American Joint Commission on Cancer. Cancer Staging Manual. 7th Edition Springer: New York, 2010.

25 McLean IW, Foster WD, Zimmerman LE. Uveal melanoma: location, size, cell type, and enucleation as risk factors in metastasis. Hum Pathol 1982; 13: 123-132.

26 Callender G. Malignant melanotic tumors of the eye: A study of histologic types in 111 cases. Trans Am Acad Ophthalmol Otolaryngol 1931; 36: 131-142.

27 McLean IW, Foster WD, Zimmerman LE, Gamel JW. Modifications of Callender's classification of uveal melanoma at the Armed Forces Institute of Pathology. Am J Ophthalmol 1983; 96: 502-509.

28 Gamel JW, McLean IW. Quantitative analysis of the Callender classification of uveal melanoma cells. Arch Ophthalmol 1977; 95: 686-691.

29 Diener-West M, Earle JD, Fine SL, Hawkins BS, Moy CS, Reynolds SM et al. The COMS randomized trial of iodine 125 brachytherapy for choroidal melanoma: III. Initial mortality findings. COMS Report No. 18. Arch Ophthalmol 2001; 119: 969-982.

30 Schmittel A, Bechrakis NE, Martus P, Mutlu D, Scheibenbogen $\mathrm{C}$, Bornfeld $\mathrm{N}$ et al. Independent prognostic factors for distant metastases and survival in patients with primary uveal melanoma. Eur J Cancer 2004; 40: 2389-2395.

31 McLean IW, Ainbinder DJ, Gamel JW, McCurdy JB. Choroidal-ciliary body melanoma. A multivariate survival analysis of tumor location. Ophthalmology 1995; 102: 1060-1064.

32 Al-Jamal RT, Kivela T. KI-67 immunopositivity in choroidal and ciliary body melanoma with respect to nucleolar diameter and other prognostic factors. Curr Eye Res 2006; 31 : 57-67.

33 de la Cruz Jr PO, Specht CS, McLean IW. Lymphocytic infiltration in uveal malignant melanoma. Cancer 1990; 65: 112-115.

34 Whelchel JC, Farah SE, McLean IW, Burnier MN. Immunohistochemistry of infiltrating lymphocytes in uveal malignant melanoma. Invest Ophthalmol Vis Sci 1993; 34: 2603-2606.

35 Mäkitie T, Summanen P, Tarkkanen A, Kivelä T. Tumorinfiltrating macrophages $(\mathrm{CD} 68(+)$ cells $)$ and prognosis in malignant uveal melanoma. Invest Ophthalmol Vis Sci 2001; 42: 1414-1421.

36 Folberg R, Rummelt V, Parys-Van Ginderdeuren R, Woolson $\mathrm{RF}, \mathrm{Pe}^{\prime}$ er J, Gruman LM et al. The prognostic value of tumor blood vessel morphology in primary uveal melanoma. Ophthalmology 1993; 100: 1389-1398.

37 Makitie T, Summanen P, Tarkkanen A, Kivela T. Microvascular loops and networks as prognostic indicators in choroidal and ciliary body melanomas. J Natl Cancer Inst 1999; 91: 359-367.

38 Coupland SE, Campbell I, Damato B. Routes of extraocular extension of uveal melanoma: Risk factors and influence on survival probability. Ophthalmology 2008; 115: 1778-1785.

39 Diener-West M, Reynolds SM, Agugliaro DJ, Caldwell R, Cumming K, Earle JD et al. Development of metastatic disease after enrollment in the COMS trials for treatment of choroidal melanoma: Collaborative Ocular Melanoma Study Group Report No. 26. Arch Ophthalmol 2005; 123: 1639-1643.

40 Eskelin S, Pyrhonen S, Summanen P, Hahka-Kemppinen M, Kivelä T. Tumor doubling times in metastatic malignant melanoma of the uvea: Tumor progression before and after treatment. Ophthalmology 2000; 107: 1443-1449.

41 Augsburger JJ, Corrêa ZM, Shaikh AH. Effectiveness of treatments for metastatic uveal melanoma. Am J Ophthalmol 2009; 148: 119-127.

42 Shields CL, Shields JA, Shah P. Retinoblastoma in older children. Ophthalmology 1991; 98: 395-399.

43 Dryja TP, Cavenee W, White R, Rapaport JM, Petersen R, Albert DM et al. Homozygosity of chromosome 13 in retinoblastoma. N Engl J Med 1984; 310: 550-553.

44 Albert DM, Dryja TP. Recent studies of the retinoblastoma gene. What it means to the ophthalmologist. Arch Ophthalmol 1988; 106: 181-182.

45 Brantley Jr MA, Harbour JW. The molecular biology of retinoblastoma. Ocul Immunol Inflamm 2001; 9: 1-8.

46 Abramson DH. Second nonocular cancers in retinoblastoma: a unified hypothesis. The Franceschetti Lecture. Ophthalmic Genet 1999; 20: 193-204.

47 Meadows AT, Leahey AM. More about second cancers after retinoblastoma. J Natl Cancer Inst 2008; 100: 1743-1745.

48 Dimaras H, Khetan V, Halliday W, Orlic M, Prigoda NL, Piovesan B et al. Loss of RB1 induces non-proliferative retinoma: increasing genomic instability correlates with progression to retinoblastoma. Hum Mol Genet 2008; 15(17): 1363-1372.

49 Gallie BL, Rushlow DE, Yee JY, Kennett P, Boutros NL, Prigoda-Lee $\mathrm{W}$ et al. A new disease: retinoblastoma with no detectable RB1 mutations driven by MYCN. Abstract. XVth Biannual Meeting. International Society of Ocular Oncology: Buenos Aires, Nov 14, 2011.

50 Shields JA, Shields CL, Eagle RC, Blair CJ. Spontaneous pseudohypopyon secondary to diffuse infiltrating retinoblastoma. Arch Ophthalmol 1988; 106: 1301-1302.

51 Shields JA, Shields CL, Suvarnamani C, Schroeder RP, DePotter P. Retinoblastoma manifesting as orbital cellulitis. Am J Ophthalmol 1991; 112: 442-449.

52 Burnier MN, McLean IW, Zimmerman LE, Rosenberg SH. Retinoblastoma. The relationship of proliferating cells to blood vessels. Invest Ophthalmol Vis Sci 1990; 31: 2037-2040.

53 Ts'o MO, Fine BS, Zimmerman LE. The FlexnerWintersteiner rosettes in retinoblastoma. Arch Pathol 1969; 88: 664-671.

54 Ts'o MO, Zimmerman LE, Fine BS. The nature of retinoblastoma. I. Photoreceptor differentiation: a clinical and histopathologic study. Am J Ophthalmol 1970; 69: 339-349.

55 Ts'o MO, Fine BS, Zimmerman LE. The nature of retinoblastoma. II. Photoreceptor differentiation: an electron microscopic study. Am J Ophthalmol 1970; 69: 350-359.

56 Eagle Jr RC. High-risk features and tumor differentiation in retinoblastoma: a retrospective histopathologic study. Arch Pathol Lab Med 2009; 133: 1203-1209.

57 Sastre X, Chantada GL, Doz F, Wilson MW, de Davila MT, Rodriguez-Galindo $\mathrm{C}$ et al. Proceedings of the consensus meetings from the International Retinoblastoma Staging Working Group on the pathology guidelines for the examination of enucleated eyes and evaluation of prognostic risk factors in retinoblastoma. Arch Pathol Lab Med 2009; 133: 1199-1202. 
58 Chévez- Barrios P. Pathology of high-risk retinoblastoma. In Ramasubrahmanian A, Shields CL (eds). Retinoblastoma. Jaypee: New Delhi, pp 223-230.

59 Shields CL, Shields JA, De Potter P, Minelli S, Hernandez C, Brady LW et al. Plaque radiotherapy in the management of retinoblastoma. Use as a primary and secondary treatment [see comments]. Ophthalmology 1993; 100: 216-224.

60 Shields CL, Mashayekhi A, Cater J, Shelil A, Meadows AT, Shields JA et al. Chemoreduction for retinoblastoma.

Analysis of tumor control and risks for recurrence in 457 tumors. Am J Ophthalmol 2004; 138: 329-337.
61 Kaliki S, Shields CL, Shah SU, Eagle Jr RC, Shields JA, Leahey A. Postenucleation adjuvant chemotherapy with vincristine, etoposide, and carboplatin for the treatment of high-risk retinoblastoma. Arch Ophthalmol 2011; 129(11): 1422-1427.

62 Eagle Jr RC, Shields CL, Bianciotto C, Jabbour P, Shields JA. Histopathologic observations after intra-arterial chemotherapy for retinoblastoma. Arch Ophthalmol 2011; 129: 1416-1421.

63 Munier FL, Gaillard MC, Balmer A, Soliman S, Podilsky G, Moulin AP et al. Intravitreal chemotherapy for vitreous disease in retinoblastoma revisited: from prohibition to conditional indications. Br J Ophthalmol 2012; 96: 1078-1083. 